\title{
CLASS INEQUALITY IN AUSTERITY BRITAIN \\ Power, Difference and Suffering \\ [Will Atkinson, Steven Roberts e Mike Savage (orgs.), 2012, Londres, Palgrave Macmillan]
}

\author{
Tiago Carvalho \\ Universidade de Cambridge, Departamento de Sociologia, Cambridge, Inglaterra. \\ Instituto Universitário de Lisboa (ISCTE-IUL), CIES-IUL, Lisboa, Portugal.
}

O livro Class Inequality in Austerity Britain. Power, Difference and Suffering organizado por Will Atkinson, Steven Roberts e Mike Savage surge na sequência de um conjunto de outros trabalhos sobre classes sociais realizados desde há uma década. No final da década de 1990 surgiu no Reino Unido um conjunto de autores que, com base no quadro teórico desenvolvido por Pierre Bourdieu, fizeram ressurgir as classes sociais enquanto objeto científico, após o seu desvanecimento das correntes mainstream. ${ }^{1}$

Este livro tem o propósito de mostrar os efeitos das políticas implementadas nas últimas décadas no Reino Unido e como estas vieram agravar as desigualdades de classe, dando destaque à sociologia enquanto ferramenta que contribui para tornar estes fenómenos visíveis. Incorpora, deste modo, uma componente crítica, cujo intuito é o de contribuir para o debate público e político. Assim, o livro é construído sobre a seguinte premissa: "sociology is thus a means of defence against symbolic domination (which among other things, sustains material domination) and the current tropes mobilised by the Conservative/Liberal Democrat coalition government of 'fairness' and compulsory austerity, as extensions of neoliberal orthodoxy, should be no exception" (p. 3).

Como é referido, o quadro teórico proposto por Bourdieu distingue-se do de Marx e Weber. Para aquele, as classes sociais não assentam na relação com os meios de produção ou no domínio de competências ou capacidades no mercado de trabalho, mas antes na posse de vários tipos de capitais (económico, cultural e social) que em conjunto moldam a experiência social dos indivíduos. Neste sentido, no livro procura-se ir para além da dominação económica, abordando-se na grande maioria dos capítulos a dominação cultural por via de violência simbólica. Dá-se assim importância não só à luta pela distribuição como à luta pelo reconhecimento. ${ }^{2}$

1 Para um esclarecimento desta discussão ver: Will Atkinson, "Introduction: from affluence to reflexivity", em Class, Individualization and Late Modernity. In Search of the Reflexive Worker, 2010, Hampshire, Palgrave Macmillan, pp. 1-14.

2 Os autores não ficam presos ao quadro teórico em questão e inserem ao longo do livro conceitos previamente formulados, tais como habitus enquanto mundo da vida ou campo subjetivo de possibilidades. Para uma melhor compreensão destes conceitos ver: Will Atkinson, "Phenomenological additions to the bourdieusian toolbox: two problems for Bourdieu, two solutions from Schutz", Sociological Theory, 28, 2010, pp. 1-19. 
$\mathrm{Na}$ introdução deste livro Atkinson, Roberts e Savage apontam que, para além da mudança da estrutura produtiva, existiu também todo um trabalho simbólico que desacreditou as classes sociais e fez prevalecer uma visão neoliberal. Deste modo, uma parte importante do primeiro capítulo, após uma breve apresentação do quadro teórico e dos objetivos do livro, discorre sobre as alterações nos discursos desde os anos 1970 e sobre como estes legitimaram um conjunto de políticas no Reino Unido. Demonstram como promoveram o individualismo e o recuo do estado e afastaram o discurso de classe, mas mais interessante ainda é a sugestão de que os atuais atores políticos utilizam um suposto estado de exceção (no sentido dado por Agamben) para legitimar a urgência das suas políticas de austeridade, não deixando de ter como pano de fundo políticas que são de classe.

Após o capítulo introdutório inicia-se um conjunto de textos que abordam o impacto da crise a vários níveis. No capítulo 2 Will Atkinson analisa de que forma a crise económica afeta o quotidiano das diferentes classes sociais. Do capítulo 3 ao 6 (Reay; Brandley e Ingram; Robert e Evan; Gillies) o eixo central da pesquisa é a educação. Nos capítulos 7 e 8 (Clement; MacKenzie) lida-se com a estigmatização e marginalização, abordando-se também os motins de 2011. No capítulo 9 Mike Savage põe em causa a tese das broken communities, que tem legitimado um conjunto de políticas que reforçam as desigualdades. Antes da conclusão, Andrew Sayer aborda o que apelida "regresso dos ricos". No capítulo final os organizadores do livro refletem sobre os desafios à exportação do conhecimento sociológico. É importante denotar a opção por metodologias qualitativas, em que, para além das habituais entrevistas, se utiliza a observação, a etnografia ou o registo das atividades diárias daqueles que estão a ser estudados. Especifique-se um pouco mais algumas das análises realizadas.

No capítulo 2 - "Economic crisis and classed everyday life: hysteresis, positional suffering and symbolic violence" - Atkinson, que tem vindo a renovar a teoria de Bourdieu, recupera o conceito de hysteresis para mostrar o impacto diferenciado da crise nos quotidianos das classes sociais. Demonstra a transformação das condições de existência e como esta se traduziu nos consumos realizados no quotidiano. Refere existirem três tipos de orientações perante a crise: (1) a "paz com o nosso tempo", por parte daqueles que possuem nível elevado de capital cultural e económico; (2) a "arte da conservação e os seus limites", em que aqueles que estão num nível intermédio mobilizam um conjunto de estratégias para conservar o seu capital económico; e por fim (3) a "necessidade multiplicada", que envolve aqueles com menor volume de capitais e mais afetados pelo corte nos serviços do Estado. Como refere no fim, a hysteresis não se distribui de forma uniforme pelo espaço social.

Os capítulos referentes à educação abordam, na senda de Bourdieu, a escola enquanto elemento fundamental de violência simbólica. Referem de que forma as desvantagens de partida das classes dominadas acabam por se reproduzir através da internalização das classificações dominantes. Em causa está um discurso individualista que culpa os indivíduos pela sua situação e que se espelha num conjunto de políticas: "At the core of the Big Society pledge to repair and responsabilise families and communities is an enduring narrative which seeks to 
portray the poor as authors of their own misfortunes" (p. 93). O sétimo e oitavo capítulos lidam com a marginalização e a estigmatização. Em parte estes capítulos procuram também mostrar as condições sociais que estiveram por trás dos motins de 2011 em Inglaterra, entre as quais o desemprego dos jovens que vivem em espaços desqualificados.

Mike Savage, no capítulo 9 - "Broken communities?" - vem questionar os termos em que se pretende construir a Big Society e a sua iniciativa moralizadora sobre as classes dominadas. Depois de uma análise cuidada, conclui que não há um sinal óbvio de quebra moral (moral breakdown), que não se trata contudo de negar a existência de pobreza e privação, mas antes de argumentar que devemos ser cuidadosos com os discursos moralizadores ligados a estes problemas. O que parece antes acontecer é um afastamento dos cidadãos ante as instituições formais devido ao seu recuo, o que leva à retirada do interesse pela atividade cívica. Termina dizendo que esta política é hipócrita: "[...] it fails to recognise that the ethics of belonging and attachment of the affluent middle classes are very different from those seen as desirable in policy circles. [...] the affluent middle classes increasingly seek to live in environments with relatively restricted social networks [...] and make sure they live with 'people like themselves' [...] [which generates] forms of social segregation and inequality" (p. 159).

Há também um capítulo dedicado aos "ricos" por parte de Andrew Sayer "Facing the challenge of the return of the rich" - que mostra como a concentração da riqueza aumentou das últimas décadas, denunciando a negligência dada às classes dominantes pela sociologia. O ponto mais interessante e original do capítulo é a sua combinação da teoria de Bourdieu com uma abordagem moral (moral economy of class) que permite analisar as categorias morais envolvidas na legitimação do "regresso dos ricos" nos discursos populares e académicos. Como diz, a mudança existente não é apenas quantitativa (concentração da riqueza), mas qualitativa, já que na base deste aumento está uma mudança dos tipos de relações sociais em que ressurge o rentista.

No último capítulo do livro os organizadores enunciam as principais dificuldades com que se digladiam os sociólogos na exportação do seu conhecimento para o domínio público: (1) o aumento da competição na produção de conhecimento politicamente útil, com o surgimento de think-tanks que procuram justificar as opções governamentais tomadas; (2) o aumento da dependência face ao campo jornalístico, com uma maior exposição mediática que é contraditória com a análise científica; e por fim, (3) o aumento dos ataques à autonomia relativa do campo das ciências sociais por parte do estado, que vai cortando sucessivamente os financiamentos. Perante este cenário há que repensar a posição dos cientistas sociais, qual o seu potencial contributo e as eventuais estratégias para fazer vingar o seu trabalho perante dificuldades e competição acrescida.

Este livro traz, sem dúvida, um contributo importante para a reestruturação e renovação da análise de classes, ao utilizar não só um quadro teórico sensível ao impacto das desigualdades nos quotidianos pessoais, mas também ao servir-se de metodologias qualitativas. Vem dar continuidade ao trabalho previamente desenvolvido, bem como estimular o debate sobre as consequências da austeridade. Há, 
na verdade, uma vertente política e crítica que acompanha todo o livro, por duas vias: (1) através da crítica às políticas seguidas e da análise das suas consequências no quotidiano pessoal; (2) através do conceito de violência simbólica, que mostra como os discursos legitimam as políticas vigentes e as tornam aceitáveis no dia a dia.

Contudo, por vezes o livro parece fechar-se em demasia sobre condições de exclusão e marginalidade, sem nada dizer sobre a chamada "classe média" e a sua reconfiguração. Refiro aqui aqueles que detêm capital cultural ou, para utilizar a expressão de Bourdieu, os dominados dentro dos dominantes. Assim, qual foi o principal impacto sobre aqueles cujo atributo fundamental é a posse de capital cultural? Qual o seu papel na legitimação e suporte das medidas vigentes? Para além do capítulo escrito por Atkinson, não se encontram mais do que pequenos apontamentos que os referem. É também neste sentido que falta um estudo sobre mobilidade social e as mudanças na estrutura de classes nas décadas em foco para complementar a análise das alterações existentes ao nível simbólico.

Termino este texto com uma sugestão. Parece haver homologias interessantes entre os processos e dinâmicas no Reino Unido e em Portugal num cenário de crise e austeridade. Seria, por isso, importante estabelecer um programa de trabalho que, tendo em conta as últimas décadas, estudasse as alterações ao nível dos discursos, para além das modificações na estrutura de classes. Falta estudar em Portugal, de forma aprofundada, o quotidiano das diferentes classes sociais, o impacto da crise económica e das medidas de austeridade, bem como entender as formas de violência simbólica existentes.

Tiago Carvalho. Doutorando no Departamento de Sociologia da Universidade de Cambridge; investigador do CIES-IUL, Instituto Universitário de Lisboa (ISCTE-IUL), Avenida das Forças Armadas, 1649-026, Lisboa. E-mail:

tmlc@cam.ac.uk 